\title{
Methylene blue during cardiopulmonary bypass to treat refractory hypotension in septic endocarditis
}

\author{
M. Grayling, MB, BS, FRCA, ${ }^{a}$ and C. D. Deakin, MA, MD, MRCP, FRCA, ${ }^{\text {b }}$ Southampton, United Kingdom
}

$\mathrm{M}$ ethylene blue inhibits the enzyme guanylate cyclase, avoiding the cyclic guanosine $3^{\prime} 5^{\prime}$-monophosphate (cGMP)-dependent vasorelaxant effects of nitric oxide in the smooth muscle of vessels. As well as its uses in the treatment of methemoglobinemia and malaria and as a medical dye, methylene blue has been used to treat refractory vasoplegia after cardiopulmonary bypass (CPB), anaphylaxis, and septic shock. ${ }^{1,2} \mathrm{We}$ describe the first case of methylene blue used in the CPB prime and in the context of refractory hypotension in a patient undergoing valve replacement surgery for infective endocarditis.

\section{Clinical Summary}

A 72-year-old man weighing $80 \mathrm{~kg}$ was admitted for investigation of a 3-month history of worsening shortness of breath associated with malaise, rigors, and swollen ankles. His standard daily prescription included human isophane insulin (Insulatard Nph Human), ramipril at $2.5 \mathrm{mg}$, and furosemide at $40 \mathrm{mg}$. Examination revealed a temperature of $37.3^{\circ} \mathrm{C}$, a blood pressure of $170 / 53 \mathrm{~mm}$ $\mathrm{Hg}$, and a regular collapsing pulse of 105 beats/min. There was also a loud early diastolic murmur at the left sternal edge and a loud pansystolic murmur at the apex. Abnormal results of routine blood tests included a C-reactive protein level of $69.2 \mathrm{mg} / \mathrm{L}$ and a white blood cell count of $16.4 \times 10^{9}$ cells/L. A transthoracic echocardiogram showed two large, highly mobile vegetations on the aortic valve, with resultant severe aortic regurgitation and a thickened anterior mitral valve leaflet with moderate mitral regurgitation. The patient's left ventricle was not dilated and was noted to have reasonable function. A diagnosis of infective endocarditis was made, and surgery was planned for the next day.

The patient received lorazepam at $1 \mathrm{mg}$ by mouth, morphine at $10 \mathrm{mg}$ intramuscularly, and metoclopramide at $10 \mathrm{mg}$ intramuscularly 1 hour before the operation. Radial arterial and peripheral venous catheters were inserted under local anesthesia. Anesthesia was induced with midazolam at $8 \mathrm{mg}$, fentanyl at $500 \mu \mathrm{g}$, and pancuronium bromide at $8 \mathrm{mg}$. The trachea was intubated, and the patient received mechanical ventilation with $50 \%$ oxygen to main-

\footnotetext{
From Shackleton Department of Anaesthesia, Southampton General Hospital, Southampton, United Kingdom.

Received for publication June 27, 2002; accepted for publication July 10, 2002.

Address for reprints: M. Grayling, MB, BS, FRCA, 4 Hazeldean Court, Nuthatch Close, Rowlands Castle, Hampshire PO9 6HA, United Kingdom (E-mail: mgrayling@doctors.org.uk; charlesdeakin@doctors.org.uk).

J Thorac Cardiovasc Surg 2003;125:426-7

Copyright $\odot 2003$ by The American Association for Thoracic Surgery $0022-5223 / 2003 \$ 30.00+0$

doi: $10.1067 / \mathrm{mtc} .2003 .140$
}

tain normocapnia. Anesthesia was maintained with isoflurane up to $1.2 \%$.

Persistent hypotension was treated with phenylephrine hydrochloride boluses to a total dose of $1.6 \mathrm{mg}$ before CPB. A dopamine infusion was commenced at $5.2 \mu \mathrm{g} /(\mathrm{kg} \times \mathrm{min})$, and a norepinephrine infusion was started, increasing to $0.02 \mu \mathrm{g} /(\mathrm{kg} \times \mathrm{min})$. Despite this, the blood pressure remained low at $100 / 22 \mathrm{~mm} \mathrm{Hg}$. Subsequent pulse contour analysis with the PulseCO system (LiDCO, London, United Kingdom), measured a cardiac output of $6.0 \mathrm{~L} / \mathrm{min}$ and a systemic vascular resistance (SVR) of 550 dynes $\times \mathrm{s} / \mathrm{cm}^{5}$. On the basis of refractory hypotension and a low SVR, $160 \mathrm{mg}$ methylene blue ( $2 \mathrm{mg} / \mathrm{kg}$ ) was added to the pump prime before the start of $\mathrm{CPB}$, and once $\mathrm{CPB}$ was established a central venous infusion was commenced at $1 \mathrm{mg} /(\mathrm{kg} \times \mathrm{h})$. Dopamine was continued at $4.2 \mu \mathrm{g} /(\mathrm{kg} \times \min )$ during $\mathrm{CPB}$, but the norepinephrine was stopped.

Surgery was uncomplicated with the removal of both the mitral and aortic valves and replacement with prosthetic 29-mm CarboMedics and 25-mm CarboMedics Top Hat valves (Sulzer CarboMedics Inc, Austin, Tex), respectively.

During CPB no further phenylephrine or norepinephrine was used, and mean blood pressure was maintained at $50 \mathrm{~mm} \mathrm{Hg}$. Separation from CPB was achieved with dopamine at $4.2 \mu \mathrm{g} /$ $(\mathrm{kg} \times \mathrm{min})$ and methylene blue at $0.5 \mathrm{mg} /(\mathrm{kg} \times \mathrm{h})$. The CPB time was 155 minutes, and the crossclamp time was 124 minutes. Five minutes after CPB, the blood pressure was $118 / 54 \mathrm{~mm} \mathrm{Hg}$, the heart rate was 103 beats/min in sinus rhythm, the cardiac output was $3.3 \mathrm{~L} / \mathrm{min}$, and the SVR was 1600 dynes $\times \mathrm{s} / \mathrm{cm}^{5}$. Methylene blue was continued until 30 minutes after CPB. There were no episodes of cardiac ischemia or arrhythmia after CPB. Before CPB the ratio of $\mathrm{PaO}_{2}$ to inspired oxygen fraction was $31 \mathrm{kPa}$, whereas after CPB it dropped to $14 \mathrm{kPa}$. The patient was admitted to the cardiothoracic intensive care unit and extubated 15 hours later. Subsequent blood and valve cultures isolated Streptococcus mitis.

\section{Discussion}

Infective endocarditis is a life-threatening condition that occasionally necessitates emergency valve replacement. It has a spectrum of clinical presentation and is associated with a systemic inflammatory response and the release of endothelial nitric oxide. Many of the drugs used in cardiac anesthesia and the process of CPB itself may exacerbate the reduction in SVR through both similar and unknown mechanisms. ${ }^{1}$ In this case there was a clear temporal relationship with the administration of methylene blue and the reduced quantities of vasopressors required to maintain normotension through an increase in the SVR.

Sepsis is characterized by arterial vasodilatation, a high cardiac output despite myocardial depression, and a decreased sensitivity of the heart and peripheral vessels to sympathomimetic agents. The myocardial depression and relative insensitivity to sympathomimetic agents may be mediated in part by nitric oxide. This has been 
demonstrated in vitro by the inhibition of vascular smooth muscle and cardiomyocyte contraction by serum from patients with sepsis. ${ }^{3}$ Methylene blue inhibits this process by decreasing intracellular cGMP concentrations through guanylate cyclase inhibition, and it increases myocardial function, arterial pressure, and oxygen delivery after a single dose. ${ }^{4}$ Nitric oxide has many cGMP effects, such as microbiocidal properties and tumor cell cytotoxicity. Inhibition of guanylate cyclase may respect these cGMP-independent effects as compared with other compounds, such as L-arginine analogs, thus incurring other clinical benefits.

Detrimental effects of methylene blue on gas exchange may occur through a process of pulmonary vasoconstriction and disruption of cGMP-dependent ventilation-perfusion matching. In contrast, however, hypoxic vasoconstriction in normal animal lungs is in part mediated by decreases in nitric oxide and cGMP production. ${ }^{5}$ Although we demonstrated a fall in the ratio of $\mathrm{PaO}_{2}$ to inspired oxygen fraction immediately after $\mathrm{CPB}$, it would be difficult to attribute this solely to the effects of methylene blue.

Other uncommon side effects described with the use of methylene blue include cardiac ischemia and arrhythmias. Although neither occurred in this case, side effects may become a problem in patients with critical coronary perfusion or an irritable myocardium. Heparin neutralization by methylene blue has been described; however, we had no difficulties with anticoagulation while the patient was on CPB. ${ }^{6}$

\section{Conclusion}

Patients with an ongoing systemic inflammatory response as a result of infective endocarditis and those who require $\mathrm{CPB}$ for emergency valve replacement may demonstrate resistant hypotension related to vasoplegia. Methylene blue should be added to the CPB prime $(2 \mathrm{mg} / \mathrm{kg})$ and continued as an infusion $(0.25-2 \mathrm{mg} /$ $[\mathrm{kg} \times \mathrm{h}])$ to ameliorate this hypotension. Such a regimen may be extended to other clinical circumstances in which resistant hypotension is contributed to by activation of the nitric oxide pathway, such as anaphylaxis and CPB.

\section{References}

1. Evora PR. Should methylene blue be the drug of choice to treat vasoplegias caused by cardiopulmonary bypass and anaphylactic shock? J Thorac Cardiovasc Surg. 2000;119:632-4.

2. Kirov MY, Evgenov OV, Evgenov NV, Egorina EM, Sovershaev MA, Sveinbjornsson B, et al. Infusion of methylene blue in human septic shock: a pilot, randomized, controlled study. Crit Care Med. 2001; 29:1860-7.

3. Hollenberg SM, Cunnion RE, Parrillo JE. Effect of septic serum on vascular smooth muscle: in vitro studies using rat aortic rings. Crit Care Med. 1992;20:993-8.

4. Daemen-Gubbels CR, Groeneveld PH, Groeneveld AB, van Kamp GJ, Bronsveld W, Thijs LG. Methylene blue increases myocardial function in septic shock. Crit Care Med. 1995;23:1363-70.

5. Hyhan AL, Lippton HL, Kadowitz PJ. Methylene blue prevents hypoxic pulmonary vasoconstriction in cats. Am J Physiol. 1991;260(2 Pt 2):H586-92.

6. Kikura M, Lee MK, Levy JH. Heparin neutralization with methylene blue, hexadimethrine, or vancomycin after cardiopulmonary bypass. Anesth Analg. 1996;83:223-7. 